38. Schori H. Vaccination for protection of retinal ganglion cells against death from glutamate cytotoxicity and ocular hypertension: implications for glaucoma / PNAS. 2001. - V. 98. - № 6. - P. 3398-3403.

39. Shen F., Chen B., Danias J. Glutamate-induced glutamine synthetase expression in retinal Muller cells after shortterm ocular hypertension in the rat / Invest. Ohthalmol. Vis. Sci. - 2004. - V. 45. - P. 3107-3112.

40. Sucher N. J., Lipton S. A. Molecular basis of glutamate toxicity in retinal ganglion cells / Vision Res. - 1997. V. 37. - № 24. - P. 3483-3493.

41. Tezel G., Yang X, Cai J. Proteomic identification of oxidatively modified retinal proteins in a chronic pressureinduced ret model of glaucoma / Invest. Ophthalmol. Vis. Sci. - 2005. - V. 46. - P. 3177-3187.
42. Wamsley S., Gabelt B. T., Dahl D. B. Vitreous glutamate concentration and axon loss in monkeys with experimental glaucoma / Arch. Ophthalmol. - 2005. - V. 123. - P. 64-70.

43. Vorwerk C. K., Lipton S. A. Chronic Low-dose glutamate is toxic to retinal ganglion cells / Invest. Ophthalmol. Vis. Sci. - 1996. - V. 37. - № 8. - P. 1618-1624.

44. Vorwerk C. K., Naskar R. Depression of retinal glutamate transporter function leads to elevated intravitreal glutamate levels and ganglion cell death / Invest. Ophthalmol. Vis. Sci. - 2000. - V. 41. - P. 3615-3621.

45. Yoles E., Schwartz M. Elevation of intraocular glutamate levels in rats with partial lesion of the optic nerve / Arch. Ophthalmol. - 1998. - V. 116. - P. 906-910.

Поступила 16.02.2012 Рецензент д. м. н. Н. Ф. Леус

\title{
STUDY OF THE CYCLE OF NEUROTOXIC TRANSMITTER - GLUTAMATE IN THE RETINA IN EXPERIMENTAL GLAUCOMA
}

\author{
Serdyuk V. N. \\ Dnepropetrovsk, Ukraine
}

The work was made on the rabbits with modeled glaucoma. There were determined the level of glutamate and glutamine, the activity of the enzymes of glutamine synthetase, glutamatoxidase and glutaminase in the retinal tissues and optical nerve in the dynamics of development of the glaucoma process. The results obtained are evidence of the increase in the content of glutamate and activity of the enzyme glutaminase.

\section{Обзор литературы}

УДК 617.771-009.11:616.833.17-071-08:616.8-089(048.8)

\section{КЛИНИКА И ЛЕЧЕНИЕ ПАРАЛИТИЧЕСКОГО ЛАГОФТАЛЬМА У БОЛЬНЫХ С НЕЙРОХИРУРГИЧЕСКОЙ ПАТОЛОГИЕЙ}

\author{
Л. В. Задоянный, канд. мед. наук, В. М. Жданова, канд. мед. наук, \\ Н. Н. Братусь, врач \\ ГУ «Институт нейрохирургии им. акад. А. П. Ромоданова НАМН Украины», г. Киев
}

\begin{abstract}
Нейропаралітичний лагофтальм у хворих з нейрохірургічною патологією особливо часто спостерігається у пацієнтів, оперованих з приводу пухлин задньої черепної ямки та у пацієнтів з важкою черепно-мозковою травмою. Проаналізовані результати консервативного та хірургічного лікування нейропаралітичного кератиту, надані рекомендації лікування хворих з нейропаралітичним лагофтальмом,
\end{abstract}

Лагофтальм - зияние глазной щели и невозможность закрыть глаз, даже при самом сильном волевом усилии. Паралитический лагофтальм наблюдается у пациентов с нарушением функции лицевого нерва (ЛН). Первичный неврит ЛН возникает при переохлаждении, вирусной инфекции. Вторичный может быть вызван черепно-мозговой или кранио-орбитальной травмой, опухолями головного мозга, базальным менингитом, заболеваниями уха или слюнных желез, врожденными уродствами развития и др. Лагофтальм развивается в результате денервации круговой мышцы глаза, отвечающей за нормальный тонус век, мигательный рефлекс, произвольное закрытие и зажмуривание глаз. Выраженный лагофтальм характерен для периферического поражения ЛН. Кроме того, в этот симптомокомплекс входит слабость мимических мышц соответствующей половины лица, клини-

( Л. В. Задоянный, В. М. Жданова, Н. Н. Братусь, 2012 
чески проявляющаяся асимметрией лица в покое, а также значительной асимметрией при выполнении волевых движений. На пораженной половине лица пациент не может поднять бровь, наморщить лоб, зажмурить глаз, надуть щеку, улыбаться $[3,5,9,25,32]$.

Легкая ранимость ЛН обусловлена его сложной топографической анатомией. Волокна ЛН берут свое начало от двигательных ядер, находящихся в латеральной части переднего отдела Варолиевого моста. В стволе мозга ЛН делает петлю вокруг ядра VI черепного нерва (ЧН), в результате чего патология ствола часто сопровождается поражением обоих нервов. ЛН выходит из ствола в месте соединения с мостом, каудальнее от V ЧН и приблизительно на 1,5 мм впереди, медиальнее и кверху от VIII ЧН. Дальше с VIII ЧН и промежуточным (n.Wrisberg) проходит через мосто-мозжечковый угол, а потом через внутренний слуховой проход попадает в височную кость в фаллопиев канал. В области дна внутреннего слухового прохода ЛН густо покрыт арахноидальной оболочкой, этот участок нерва очень чувствителен к сдавлению, возникающему при отеке корешка нерва. Нерв содержит около 7-10 тыс. нервных волокон. Костная оболочка защищает нерв, но в то же время делает его очень ранимым при развитии отека. Через шило-сосцевидное отверстие ЛН выходит из височной кости и делится на височно-лицевую и шейно-лицевую веточки, образуя гусиную лапку (pes ancerinus). Основными конечными веточками ЛН являются височная, скуловая, щечная, нижнечелюстная и шейная.

В зависимости от уровня поражения ЛН наблюдается та или иная клиническая картина. Парез мимических мышц половины лица и слезотечение возникают при поражении ЛН после выхода из черепа. Нарушения вкуса на передних 2/3 языка свидетельствуют о поражении ЛН над отхождением барабанной струны. Наличие шума, гула (явления гиперакузии) указывают на уровень ниже стременного нерва. Поражение ЛН в фаллопиевом канале до его колена сопровождается сухостью глаза, во внутреннем слуховом проходе - глухотой. Прогностически тяжелым для пациента является уровень выше коленчатого ганглия (ganglion geniculi), на что указывает отсутствие слезной секреции. Сухость глаза, сочетающаяся с лагофтальмом, способствует развитию трофических нарушений роговой оболочки глаза [16].

Особенно часто и прогностически неблагоприятно лагофтальм протекает у больных, оперированных по поводу опухолей задней черепной ямки. Иногда, во время операционных вмешательств, по тем или иным причинам не удается сохранить анатомическую целостность ЛН. Например, интраоперационное повреждение ЛН во время выделения вестибуло-кохлеарных неврином, по дан- ным M.Saami, наблюдается у 2,8 \% больных. При патологии в области мосто-мозжечкового угла в процесс часто вовлекается тройничный (V) нерв, это служит отягчающим фактором в развитии нейротрофических паралитических кератитов. Отводящий (VI) ЧН очень чувствителен, его дисфункция возникает даже при минимальном смещении корешка нерва с капсулы опухоли во время удаления вестибуло-кохлеарных неврином. Если у пациентов имеются глазодвигательные нарушения, связанные с поражением VI ЧН, то нейропаралитические кератиты, как правило, имеют тяжелое и затяжное течение.

Переломы костей основания черепа - преимущественно средней черепной ямки - приводят к повреждению черепных нервов, в первую очередь, VII, VIII, в тяжелых случаях - VI ЧН. Восстановление функции пораженных черепных нервов является очень важной и сложной задачей, т.к. им в некоторых случаях принадлежит ведущая роль в инвалидизации пациентов, они являются фактором, ухудшающим качество жизни $[10,22,29]$.

Лечение дисфункции ЛН у нейрохирургических больных должно быть строго индивидуальным и может состоять из простого наблюдения, назначения фармакологических препаратов, физиотерапевтических методов, хирургических вмешательств. Медикаментозная терапия включает применение антихолинэстеразных, сосудистых препаратов, витаминотерапии. Из физиотерапевтических методов используется ультразвуковая терапия малой мощности $(0,05-0,2$ Вт/смI) в импульсном или постоянном режиме. Хорошо зарекомендовал себя ультрафонофорез гепариновой или гидрокортизоновой мази. Обязательным является проведение нейромышечной электростимуляции пораженной половины лица точечным электродом, позволяющим целенаправленно воздействовать на определенные мимические мышцы и особенно - на круговую мышцу глаза. Назначается поверхностный массаж лица и шейно-воротниковой зоны, а также специальный комплекс лечебной физкультуры. Хорошие результаты получены при использовании импульсной магнитотерапии (аппарат БТЛ 5000) на заушную область и пораженную половину лица [4, $6,7,11,12,13,30]$.

Несмотря на то, что дисфункция ЛН приводит к выраженному косметическому дефекту и существенным образом отражается на социальной жизни пациента, самое серьезное осложнение касается глаз. Денервация круговой мышцы глаза, отвечающей за нормальный тонус век, отсутствие мигательного рефлекса, невозможность произвольного закрытия и зажмуривания глаз приводят к тому, что лагофтальм становится одним из ведущих факторов возникновения нейропаралитического кератита. При сочетании повреждения ЛН с тройничным (V) 
и отводящим (VI) ЧН опасным осложнением является поражение роговой оболочки с развитием эрозий, кератита, язвенных поражений, в тяжелых случаях возникновение перфораций и слепоты.

Лечение паралитического лагофтальма у больных должно быть комплексным, с учетом основного заболевания. Существующие методы можно разделить на две группы: консервативные и хирургические. Консервативные методы используются у пациентов с прогнозируемым быстрым восстановлением функции ЛН. При незначительном лагофтальме обязательным является применение препаратов искусственной слезы и различных гелей корнеропротекторов, инстиллируемых в конъюнктивальную полость, что способствует профилактике высыхания конъюнктивы. Закапывание в глаз искусственной слезы при необходимости проводится многократно в течение суток. Также рекомендуется увлажнение помещения и ношение повязки, удерживающей глаз в закрытом состоянии. Перед сном пациенты обязательно должны наносить увлажняющие гели в конъюнктивальную полость.

При появлении признаков раздражения слизистой оболочки (покраснение, инъекция склеры) в тех случаях, когда прогнозируется достаточно быстрое восстановление функции ЛН, хорошо зарекомендовал себя способ введения воздуха под кожу верхнего и нижнего века. Таким образом вызывается механическое сближение век, глаз закрывается, это препятствует высыханию слизистой оболочки. Временное устранение лагофтальма способствует ликвидации воспалительных изменений и улучшению трофики роговой оболочки глаза.

У пациентов с прогнозируемым длительным периодом восстановления функции ЛН (6 месяцев и больше), с целью профилактики развития осложнений со стороны глазного яблока эффективным является проведение блефароррафии - полной или частичной. Блефароррафия может быть применена как временный способ в комплексном лечении нейропаралитического кератита, рассчитанный на длительный период (3-4 года) или же постоянно. Чаще всего в наружном углу глазной щели проводится тарзоррафия одним-двумя П-образными швами.

В связи с отсутствием нормального тонуса мышц пораженной половины лица под давлением силы тяжести и прогрессирования атрофических процессов у некоторых больных происходит выворот нижнего века. Это приводит к увеличению лагофтальма, что усугубляет проявления кератита. Для нормализации положения нижнего века выполняются операции по укорочению нижнего века, дополнительно производят наружную тарзорафию и рефиксацию латеральной связки век к надкостнице. В нашем Институте нейрохирургии чаще всего выполняют операцию на нижнем веке по методу Кунт-Шимановского, оказавшуюся очень эффективной, особенно в сочетании с блефароррафией. У больных с нарушением анатомической целостности ЛН, а также у пациентов с отсутствием клинической и электронейромиографической динамики восстановления функции нерва (согласно шкале House-Brackmann - пятая степень нарушения) проводится операция невротизации [15,20,35]. При невротизации ЛН сшивается с подъязычным (XII) или с дополнительным (XI) ЧН. Неприятным моментом для больных после такой операции бывает временная незначительная дизартрия, девиация языка, но на протяжении 1-2 месяцев больные привыкают, речевые нарушения регрессируют. В дальнейшем развивается атрофия мышц языка на стороне нерва-донора, однако на речевую функцию это не влияет. Диаметры сечения сшиваемых нервов почти одинаковы, но все же диаметр подъязычного ближе к лицевому, поэтому больше волокон прорастает из IX нерва, и наблюдаются лучшие результаты восстановления функции ЛН. Это способствует уменьшению проявлений, а в дальнейшем ликвидации экспозиционной кератопатии [14, 26, 27].

Кроме вышеперечисленных способов лечения паралитического лагофтальма, используемых в Институте нейрохирургии, в литературе имеются различные сообщения о применении тех или иных методов. Читатели могут обратиться к работе [1], где авторы дают более развернутую характеристику хирургических способов лечения паралитического лагофтальма. Мы же попытаемся осветить те методики, с результатами которых нам пришлось столкнуться при наблюдении за нашими пациентами и проанализировать их сильные и слабые стороны. Например, одной из перспективных методик одно время [24] было введение ботулотоксина типа А в мышцу, поднимающую верхнее веко. Это приводит к полному или частичному опусканию верхнего века, что некоторым образом защищает роговицу от внешнего воздействия. Этот способ, по нашему мнению, малоприемлем, т.к. чреват малопрогнозируемым по величине птозом и использовать его у больных с ожидаемым восстановлением функции ЛН нецелесообразно.

Применяется сужение глазной щели с помощью проведения силиконовой нити через верхнее и нижнее веко с фиксацией концов в натянутом состоянии [1,2]. Путем повторных попыток сомкнуть и разомкнуть веки интраоперационно выбирается оптимальное натяжение нити. Данная операция менее травматична и косметический эффект несколько лучше, чем при проведении тарзорафии или блефароррафии, однако полное открытие век становится невозможным. Из осложнений методики отмечают прорезывание нити, воспалительные 
реакции инфекционной и неинфекционной этиологии.

Для дополнительного опущения верхнего века используют удлинение мышцы, поднимающей верхнее веко, в том числе с применением имплантатов, с целью утяжеления века. Одним из способов утяжеления является хондропластика верхнего века: под круговую мышцу глаза вводится трансплантат хряща или размельченный хрящ в область тарзальной пластинки, моделированный в виде пластины, величина которой варьирует от степени лагофтальма [8]. Применяется силиконовая губка, ее помещают в предварительно сформированный тоннель под тарзоорбитальной фасцией. Авторы предлагают данную методику для компенсации атрофированных орбитальных тканей при отсутствии восстановления функции ЛН. Мы разделяем мнение авторов [2], что этот способ далек от совершенства, т.к. невозможно прогнозировать величину коррекции лагофтальма и сложно сформировать имплантат заданной массы. Выполняются имплантации магнитов в верхнее и нижнее веко [33], довольно часто авторы наблюдали их отторжение и выход через кожу, что объясняется прогрессированием атрофических процессов в периорбитальных тканях при длительно существующем параличе ЛН

Для коррекции используются монолитные имплантаты, выполненные из различных материалов: золота - пробы 99,99, медицинской стали [18, 19, $21,28]$. Однако оказалось, что существует гиперчувствительность IV типа к золоту, что является основной причиной развития воспалительной реакции и выхода имплантата [34]. Имплантируется металлическая пружина $[17,23]$, особенно при неэффективности или невозможности выполнения других методов коррекции. Осложнения методики: отторжение, дислокация или прорезывание через кожу, а также возникновение роговичного астигматизма в связи с локальными изменениями тарзальной пластинки под тяжестью пружины и давлением на глазное яблоко.

Малая травматичность, хороший косметический эффект и обратимость результата в случае восстановления функции ЛН делают перспективной методику введения геля на основе гиалуроновой кислоты. Подобные гели широко используются в косметологии для восстановления утраченного объема тканей [31].

Таким образом, в данной работе мы попытались представить обзор методов, используемых при лечении паралитического лагофтальма. У больных с нейрохирургической патологией лечение паралитического лагофтальма должно быть комплексным с широким применением физиотерапевтических методов лечения. Задачей максимум является восстановление функции ЛН. У пациентов с ожидаемым быстрым восстановлением функции ЛН необходи- мо проводить консервативные методы или вмешательства малой травматичности, дающие хороший косметический и лечебный результат, а также возможность устранения последствий хирургического лечения в случае восстановления функции ЛН. При тяжелых поражениях ЛН с длительным периодом восстановления, или при прогнозируемом минимальном восстановлении функции ЛН методами выбора являются хирургические методы коррекции лагофтальма - блефароррафия или другие методы.

\section{ЛИТЕРАТУРА}

1. Агафонова Е. И., Груша Я. О. Хирургические способы лечения паралитического лагофтальма // Вестник офтальмологии. - 2010. - № 5. - С.48-52.

2. Волков В. В., Бржеский В. В., Ушаков Н. А. Офтальмохирургия с использованием полимеров. - СПб., 2003. - C.23-42.

3. Горохов А. А. Отонейрохирургия: Руководство для врачей. - СПб: Питер, 2000. - 333 с.

4. Деклараційний патент України на винахід № 69208, МПК 7 A61 N7/00, Україна, Спосіб лікування невриту лицьового нерву / Жданова В. М., Цимбалюк В. І. - № 2003 1211595; заявл. 15.12.2003 ; опубл. 16.08.2004. - Бюл. № 8, 2004.

5. Деконенко Е. П., Леоньева И. Я., Мартыненко И. Н. и др. Невриты лицевого нерва и их связь с вирусами герпеса // Журн. неврол. и психиатрии им. С. С.Корсакова. - 2000. - № 6. - С.58-59.

6. Жданова В. М. Магнітотерапія в комплексному лікуванні дітей та підлітків з невропатією лицьового нерва // Зб. матер. практ. семінару з міжн. уч. «Використання фізіотерапевтичних методів в реабілітації дітей-інвалідів з порушенням нервової системи та опорно-рухового апарату». - Київ. 2011. - 24-27.

7. Жданова В. М., Скобська О. Є., Задоянний Л. В. Комплексне відновне лікування хворих з черепномозковою травмою та переломом основи черепа // Журн. мед. реабилит., курортолог., физиотер. № 2(54). - 2008. - С.10-13.

8. Зайкова М. В. Пластическая офтальмохирургия. 2-е изд. - М., 1980. - С.28-43.

9. Зозуля Ю. А., Федирко В. О. Нейроваскулярные компрессионные синдромы задней черепной ямки // Мат.III съезда нейрохирургов России. - СПб. 2002. - С.465-466.

10. Кеворков Г. А., Жданова В. М. Ураження лицьового нерва при черепно-мозковій травмі у дітей різних вікових груп та сучасне відновне лікування // Укр. нейрохір. журн. - 2006. - № 4. - С.31-34.

11. Патент на корисну модель № 25397U, МПК А61 N7/00, Україна, Спосіб лікування порушення функції лицевого нерва у нейрохірургічних та неврологічних хворих / Жданова В. М., Цимбалюк В. І., Трибель О. В., Богомаз Г. І. - № u2007 02757; заявл. 15.03.2007 ; опубл. 10.08.2007. - Бюл. № 12.

12. Патент на корисну модель № 28768, Україна, MПКА61N7/00 Спосіб лікування нейропатії лицьового нерву, ускладненої розвитком нервово-м'язової контрактури у нейрохірургічних та неврологічних хво- 
рих / Цимбалюк В. І., Жданова В. М., Трибель О. В., Грабарчук О. Ю. - № u2007 07896; заявл. 12.07.2007 ; опубл. 25.12.2007. - Бюл. № 21.

13. Цимбалюк В. І., Жданова В. М. , Спиридонова М. В., Трибель О. В. Лікування хворих з невропатією лицьового нерва, ускладненою нервово-м'язовою контрактурою // Укр. неврологіч.журн. - № 1(6). - 2008. C.96-99.

14. Цимбалюк В. І., Третяк І. Б., Хонда.О. М. Хірургічне лікування хворих з патологією лицьового нерва // Журн. вушних, носових і горлових хвороб. - 1999. № 3, додаток. - С.474-477.

15. Чеботарьова Л. Л., Третяк І. Б., Третякова А. І. Інструментальні методи діагностики ураження лицьового нерва (огляд літератури) // Укр. нейрохірургічний журн. - 2001. - № 2. - С.114-115.

16. Яхно Н. Н., Штульман Д. Р., Мельничук П. В. Болезни нервной системы: Руководство для врачей. - 3-е изд. - М.:Медицина, 2003. - С.535-543.

17. Avni-Zauberman N., Rosen N., Ben Simon G. J. Inducted corneal astigmatism by palpebral spring for the treatment of lagophthalmos eyelid // Cornea. - 2008. - Vol.27, № 6. - P.632-636.

18. Baheerathan N., Ethunandan M., Ivankovan V. Gold weight implants in the management of paralytic lagophthalmos // Int. J. Maxillofac.Surg. - 2009. - Vol.38, № $6 .-$ P.632-636.

19. Berghaus A., Neumann K., Schrom T. The platinum chain: a new upper-lid implatan for facial palsy // Arch. Fac. Plast. Surg. - 2003. - Vol.5. - P.166-170.

20. Cronin G. W., Steenerson R. L. The effectiveness of neuromuscular facial retraining combined with electromyography in facial paralysis rehabilitation // Otolaringol. Head Neck Surg. - 2003. - Vol.128, — № 4. - P.534538.

21. Dalkiz M., Gokce H. S., Aydin A., Beydemir B. Gold weight implantation for the regabilitation of the paralysed eyelid // Int. J. Maxillofac.Surg. - 2007. - Vol.36, № $6 .-$ P.522-526.

22. Darrouzet V., Duclos J. Y., Liguoro D., Truilche Y., De Bonfils C., Berear Y. P. Management of facial paralysis resulting from temporal bone fractures: our experience in 115 cases // Otolaringol. Head Neck Surg. - 2001. Vol.125, № 1. - P.77-84.

23. Demirci H., Frueh B. R. Palpebral spring in the management of lagophthalmos and exposure keratopathy sec- ondary to facial nerve palsy // Ophthalm. Plast. Reconst. Surg. - 2009. - Vol.25, № 4. - P.270-275.

24. Ellis M. F, Daniell M. An evaluation of the safety and efficacy of botulinum toxin type A (BOTOX) when used to produce a protective ptosis // Clin.Exp. Ophthalmol. 2001. - Vol.29. - P.394-399.

25. Finsterer J. Management of peripheral facial nerve palsy // Eur. Arch. Otorhinolaryngol. - 2008. - Vol.265, № 7. P.743-752.

26. Greibie M. S., Huff J. S. Selective role of parcial XI-VII anastomosis in facial reanimation // Laryngoscope. 1998. - Vol.108, № 11. - P.1664-1668.

27. Gulhius H. J., Beurskens C. H., Marres H. A. Contralateral reinnervation of midline muscles in facial paralysis // Muscle Nerve. - 2001. - Vol.24, № 12. - P.1703-1705.

28. Jayashankar N., Morwani K. P., Shaan M. G., et al. Customized gold weight eyelid implantation in paralytic lagophthalmos // J. Laryngol. Otol. - 2008. - Vol.122, № 10. - P.1088-1091.

29. Khan N., Zumstein B. Transverse clivus fracture: case presentation and significance of clinical-anatomic correlation // J. Surgical Neurology. - 2000. - V.54. - N2. - P.171-177.

30. Krukowska J. Analysis of physiotherapy outcome in patients with Bell's peripheral facial nerve palsy // Otolaryngol. Pol. - 2003. - Vol.57, № 1. - P.143-145.

31. Mancini R., Taban M., Lowinger A et al. Use of hyaluronic Acid hel in the management of paralitic lagophthalmos: hyaluronic Acid hel Changes «gold weight « // Opthal. Plast. Reconstr. Surg. - 2009. - Vol.25, № 1 P. 23-26.

32. Peitersen E. Bell's palsy: the spontaneous course of 2500 peripheral facial nerve palsies of different etiologies // Acta Otolaryngol. Suppl. - 2002. - Vol.54, № 2. - P. 4-30.

33. Reichem E., Hinzpeter E. N. Experience with magnet implantation in lagophthalmos // Klin. Mbl. Augenheilk. 1989. - Vol.22, № 2. - P.142-145.

34. Ritz M., Southwick G. J., Gory I. Gold sensitivity after gold weight eyelid insertion for facial palsy // Aesthet. Plast. Surg. - 2006. - Vol.30, № 6. - P.7333.

35. Yen T. L., Driscoll C. L., Lolwani A. K., Significance of House-Brackmann facial nerve grading global score in the setting of differential facial nerve function // Otol. Neurotol. - 2003. - Vol.24, № 1. - P.118-122.

Поступила 22.12. 2011

Рецензент д. м. н. С. И. Полякова 